\title{
Factors Determining Choice of Delivery Place among Women of Childbearing Age: A Cross-Sectional Study
}

\author{
Asmaa Saber Ghaly ${ }^{1} \&$ Neama Saad Shoukhba ${ }^{2}$ \\ 1. Assistant Professor of Obstetrics and Gynecology Nursing, Faculty of Nursing, Alexandria University, Egypt \\ 2. Lecturer of Obstetrics \& Gynecology Nursing, Faculty of Nursing, Alexandria University, Egypt
}

\begin{abstract}
Background Childbirth is a deep psychological experience that has a long-term effect on women's health. Therefore, pregnant women need to make an informed decision about where and how they will give birth. Aim of the study this study was carried out to explore the factors determining choice of delivery place among women of childbearing age. Subjects \& Method A convenience sample of 200 postpartum women were recruited by simple random sampling technique from the eight districts in Alexandria Governorate. Two tools were used for data collection. Results More than one-half (58\%) of women had fair level of knowledge about the delivery place compared to $42 \%$ who had poor knowledge. The highest percentage of them (34\%) preferred to have their future delivery at private hospitals followed by $27 \%$ of them who preferred private clinics. Conclusion Based on the findings of the present study, it could be concluded that slightly less than three - fifths $(58 \%)$ of the studied subjects had fair knowledge level regarding the delivery places. Additionally, 58\% of them had chosen the hospitals whether private or governmental as a place for future delivery due to the availability of health care providers and good supplies and facilities. Moreover, they will choose the most affordable hospital available. A positive correlation was found between the knowledge about delivery places and age, education level and residence. Recommendation Continuous monitoring of women's satisfaction with all aspects of care during delivery could aid in improvement of the quality of services and ultimately improve the women's attitude toward the different delivery places.
\end{abstract}

\section{Keywords: Factors choice, Delivery place, Childbearing age, Alexandria governorate}

\section{Introduction}

Childbirth is a deep psychological experience that has a physical, psychological, social, and existential short- and long-term effect on women's health. It also leaves lifelong bright memories for them. The impact of a birth experience can be optimistic and empowering, or pessimistic and traumatizing. Regardless of their cultural experience, women need to share their birth stories to fully integrate manner with others and to be free from any negative consequences related to childbirth (Pillitteri, 2010). The normal childbirth process is defined as "the series of events by which the fetus and placenta are expelled from the women's uterus". It is characterized by the following: the fetus is born at full term, the fetus is viable and single, the fetal presentation is vertex, the process of labor is completed spontaneously, the process of labor is completed through the natural passages as well as the time of labor doesn't exceed 24 hours. Negligence of this crucial period may have negative consequences and ultimately add to maternal morbidity and mortality (Murray \& McKinney, 2014).

According to the World Health Organization (WHO), the maternal mortality ratio (MMR) estimated worldwide in the year 2010 was 210 deaths/100.000 live births among women aged 15-49 years, which shows a decline of $47.5 \%$ from the level in 1990 which was around 400 death / 100,000 live births. Then in 2013 MMR showed a second decline of $45 \%$ worldwide. In 2015 MMR it had shown a further decline of $43 \%$ worldwide ${ }^{(10)}$. In Egypt, the national maternal mortality study (2008), did report that the MMR had dramatically decreased from $174 / 100.000$ live births in 1992-1993 to only84/100.000 live births in 2000. A further decline had occurred from 67.6/100.000 live births in 2005 to 66/100.000 live births in 2010 and finally 33/100.000 in 2015. This decrease in MMR indicates the effort of the country in the accomplishment of sustainable development goals. One of the cornerstones to achieve these goals is the provision of quality antenatal and natal care (World Health Organization [WHO], 2015; Campbell et al., 2019).

However, there are many objectives for caring of the parturient woman such as: firstly, reduce maternal long- and short-term birth complications such as hemorrhage, eclampsia, infection, unsafe abortion, and obstructed labor, secondly attain a healthy mother and neonate with the least possible level of intervention that is compatible with safety. This approach implies that in normal labor there should be an effective reason to interfere with the normal 
process. Thirdly, an achievement of the feeling of happiness and satisfaction for all women during labor and delivery; these feelings are affected by the birth environment. Therefore, pregnant women need to make an informed decision about where and how they will give birth. However, different birth settings provide pregnant women with different opportunities for labor and delivery ( Ibone et al., 2018).

There are three settings for delivery such as home birth setting, birth centers settings as well as private and governmental hospital settings. Homebirth is defined as delivery at the place of residence usually conducted by traditional birth attendants, who are generally available, have some birth experiences, come from the community as well as know the culture and less expensive. There are many benefits for homebirth as some women for many reasons including more intimate family-setting; more control of the labor process; interventions and lowering costs. Also, some women are more comfortable and relaxed at home; as a result, they will have better labor progress and enjoy the birth experience at home. As well as there is a lot of evidences showing that homebirth is safe for low-risk women (Zielinski et al., 2015).

The American Association of Birth Centers considers the birth center as a home-like setting where health care providers provide family-centered care to healthy pregnant women. Most of these centers are located separately from hospitals. Where a hospital setting can accommodate a variety of birth experiences; hospital birth settings have many benefits such as availability of skilled birth attendants, availability of needed equipment, and supplies. Besides, usually the setup of the rooms is created to provide a nurturing environment, with warm, soothing colors and features. This provides a home-like atmosphere which can be very comforting for new mothers (American Association of Birth Centers [AABC], 2015)

Many factors are determining the choice of delivery places. The maternal satisfaction with childbirth experience is closely related to her choice and autonomy to determine where to give birth. However, little is known about what motivates women to prefer a certain place for delivery. In this context, many factors can play a role. The individual factors include age; parity; the level of education; and marital status. The household factors include family size and household wealth. The community factors include socioeconomic status, community health infrastructure, region, rural/urban residence, available health facilities and distance to health facilities. Moreover, some demographic features may affect women's choice of birth setting such as employment status and health care status(Steel et al., 2014).
Firstly, Socio-demographic factors have an impact on women's choice of birthplace especially in rural areas, where the traditions and poor conditions of the family seems to be the main causes for preferring home delivery. Most of the home deliveries were also monitored by traditional birth attendants (TBAs). Also, the women birthing in birth centers prefer places where they can find Complementary and Alternative Medicine (CAM) practitioners. In contrast, a more positive attitudes are held by women birthing in hospitals towards obstetric care (Ravi et al., 2014).

Furthermore, women's experience in relation to place of delivery had an impact on their future choices in relation to that matter; i.e. the high-risk pregnancy women usually planned hospital births. Women with normal pregnancies who delivered in hospitals, would often plan the same for the future (Coxon et al., 2015).

Risk factors may also determine the choices that are available to women. Therefore, identifying risks in pregnancy for mother and fetus are a fundamental part of antenatal care, especially in an obstetric setting. Thus, women's awareness of warning signs during pregnancy, delivery and the postpartum will allow them to make prompt decisions to seek quality care offered by skilled birth attendants (Larkin et al., 2017).

Additionally, interpersonal relationships together with continuity of care are corner stones that leads to a good birth experience. The holistic care during the childbearing process gives the woman the sense of positivity. Moreover, personal growth and continuity in care during the birth experience, help in the empowerment of both the woman and her husband (Dahlberg \& Aune, 2013).

\section{Significance of the study:}

Different delivery places provide pregnant women with different opportunities for labor and delivery. However, little is known about what motivates women to prefer a certain place for delivery. In this context, many factors can play a role. Furthermore, women's experience in relation to place of delivery had an impact on their future choices in relation to that matter; i.e. the high-risk pregnancy women usually planned hospital births. Women with normal pregnancies who delivered in hospitals, would often plan the same for the future (Coxon et al., 2015).

In this context, it is important to understand the experience of care for women who have given birth at home compared with those who have given birth in a health facility, and to analyze any differences so that services can be improved, with the aim of encouraging births in facilities, especially in areas where women still prefer home births. Moreover, the 
study results can help policymakers in allocating resources based on differences in rural and urban areas based on the attitudes of subjects. Also, the findings will be beneficial to the planners for reproductive health services to design effective educational and preventive health services.

Aim of the study:

Explore the factors determining choice of delivery place among women of childbearing age.

Research question:

What are the factors determining choice of delivery place among women of childbearing age?

\section{Materials And Method \\ Materials \\ Research design}

This was an exploratory descriptive research design.

\section{Setting}

The study was carried out at Alexandria governorate. There are eight districts in Alexandria namely: ElAgami, Borg- Elarab, West, East, Middle, El.Montaza, El-Ameria, El.Gomrok. The study was done in eight family medicine units available in 4 districts in Alexandria. These units were chosen through a multi-stage probability sampling technique as follows:

1.By simple random sampling technique four districts were picked up from the available eight districts in Alexandria governorate.

2.Two units were then selected.-.by simple random sampling techniques - from each of the four formerly selected districts totaling eight family medicin units as follows:

a) El - Agami district:

-El- Hanoville family medicine unit

-El- Bitash family medicine unit

b) El- Ameria district:

-El- Wadi family medicine unit

-El- Haouaria family medicine unit

c) El-Montaza district:

- Khorshid family medicine unit

-El- Mandara family medicine unit

d) East district:

- Smouha family medicine unit

- Abies 1 family medicine unit

\section{Subjects:}

A convenience sample of 200 postpartum women (25 from each unit) was recruited, attending the previously mentioned settings for the $6^{\text {th }}$ week's postpartum follow-up, receiving of family planning service and were willing to participate in the study. The sample size of pregnant women was estimated by using the Epi-Info 7 program, where the following parameters were applied:

- Population size $=1200 / 3$ months

- Expected frequency $=50 \%$
- Acceptable error $=10 \%$

- Confidence coefficient $=95 \%$

- Minimum sample size $=190$

- Final sample size 200 women for possible non response.

Data collection tools:

Two tools were utilized for data collection.

Tool I: Basic data structured questionnaire:

This tool was developed by the researcher. It included four parts:

Part1:Socio-demographic data such as: age, educational level, occupation, current residence, type of family, family income, and house condition.

Part2: Reproductive history: such as gravidity, parity, number of abortions, stillbirths as well as number and sex of living children.

Part3: History of last pregnancy: such as number of follow-up visits, and complications as well as receiving health teaching about warning signs of pregnancy, signs of approaching labor, delivery place and preparation for labor. In addition to the sources of these information.

Part4: History of last childbirth: such as place of delivery and reasons for delivery in this place as well as the birth attendant and postpartum complications.

Tool two: women's knowledge regarding delivery place structured interview schedule: It was developed by the researcher. It comprised 21 items regarding the following: Knowledge about delivery places as well as advantages, disadvantages, the predilection of selecting the delivery places and reasons such as cost, safety, availability of all resources and supplies facilities as well as birth attendants and their behaviors.

-The knowledge response to each item between incorrect answer or don't know (0), correct but not complete (1), correct and complete (2). For each woman, the total scores ranged from $0-42$. The total knowledge score summed up and categorized as follows:

- Poor knowledge 0 - < 14 .

- Fair knowledge 14- < 28.

- Good knowledge 28- 42.

Method

The study was executed according to the following steps:

1. An official letter from the Faculty of Nursing University of Alexandria was directed to the responsible authorities of the previously mentioned settings to obtain their permission for conducting the study.

2. Both Tools (I\&II) were developed by the researcher after a review of recent relevant literature. 
3. Both tools were submitted to three experts in the related field to assess its content validity then the necessary modifications were done.

4. Reliability of tools was accomplished by CRONBACH'S ALPHA test and the result was highly reliable $(0.820)$.

5. A pilot study was done on 20 postnatal women to test the clarity, feasibility \& applicability of the tools and the necessary modifications were done accordingly. Pilot study participants were excluded from the study.

6. After the pilot study, tools were revised, and the necessary modifications were done.

7. Field of work: Each woman was individually interviewed after receiving her care. The duration of each interview ranged between 15-30 minutes. Two days / week were specified for data collection. An average of 8-10 interviews were performed /day.

8. Ethical consideration: For each recruited subject the following issues were considered: securing the subject's informed oral consent after explaining the purpose of the study, keeping her privacy and right to withdrew at any time as well as assuring confidentiality of her data.

9. Statistical analysis: the collected data was revised, categorized, coded, computerized, tabulated, and analyzed using statistical package for social sciences (SPSS) version 20. The following statistical measures were used:

A. Descriptive statistics: included frequency, percent, and mean with standard deviation to describe the scale and categorical data.

B. Analysis of categorical data:

1. Monte Carlo exact test and ${ }^{\mathrm{MC}} \mathrm{p}$ were used to explore relationships between variables.

2. $\mathrm{P}$ value $\leq 0.05$ was considered statistically significant.

3. Pearson correlation coefficient

\section{Results}

Table (1):Distribution of the studied women according to their Socio-demographic data $(n=200)$

\begin{tabular}{|l|c|c|}
\hline \multicolumn{1}{|c|}{ Socio-demographic data } & No. & \% \\
\hline Age (year) & & 24.0 \\
\hline$-<25$ & 48 & 60.5 \\
\hline$-25-<35$ & 121 & 15.5 \\
\hline$-\geq 35$ & 31 & \\
\hline Min. - Max. & \multicolumn{2}{|c|}{$18.0-40.0$} \\
\hline Mean \pm SD. & \multicolumn{2}{|c|}{$28.50 \pm 5.48$} \\
\hline Level of education & 13 & 6.5 \\
\hline- Illiterate / read and write & 26 & 13.0 \\
\hline- Primary / preparatory & 83 & 41.5 \\
\hline- Secondary or equivalent & 75 & 37.5 \\
\hline- University education & 3 & 1.5 \\
\hline- Postgraduate studies & & 53.5 \\
\hline Occupation & 107 & 46.5 \\
\hline- Housewife & 93 & 48.5 \\
\hline- Working & & 51.5 \\
\hline Current residence & 97 & 52.0 \\
\hline- Rural & 103 & 48.0 \\
\hline- Urban & & 28.0 \\
\hline Type of family: & 104 & 49.5 \\
\hline- Nuclear & 96 & 22.5 \\
\hline- Extended & & \\
\hline Family income/month: & 56 & \\
\hline- More than enough & 99 & \\
\hline- Just enough & 45 & \\
\hline- Not enough & & \\
\hline
\end{tabular}


Table (2): Distribution of the studied women according to their Reproductive history $(n=200)$

\begin{tabular}{|c|c|c|}
\hline Reproductive health history & No. & $\%$ \\
\hline \multicolumn{3}{|l|}{ Gravidity } \\
\hline-1 & 56 & 28.0 \\
\hline-2 & 43 & 21.5 \\
\hline$-\geq 3$ & 101 & 50.5 \\
\hline Min. - Max. & \multicolumn{2}{|c|}{$1.0-6.0$} \\
\hline Mean \pm SD. & \multicolumn{2}{|c|}{$2.69 \pm 1.45$} \\
\hline \multicolumn{3}{|l|}{ Parity } \\
\hline-1 & 80 & 40.0 \\
\hline-2 & 48 & 24.0 \\
\hline$-\geq 3$ & 72 & 36.0 \\
\hline Min. - Max. & \multicolumn{2}{|c|}{$1.0-5.0$} \\
\hline Mean \pm SD & \multicolumn{2}{|c|}{$2.09 \pm 1.08$} \\
\hline \multicolumn{3}{|l|}{ No. of stillbirth } \\
\hline Min. - Max. & \multicolumn{2}{|c|}{$0.0-1.0$} \\
\hline Mean \pm SD. & \multicolumn{2}{|c|}{$0.09 \pm 0.29$} \\
\hline \multicolumn{3}{|l|}{ No of lived children } \\
\hline Min. - Max. & \multicolumn{2}{|c|}{$1.0-4.0$} \\
\hline Mean \pm SD. & \multicolumn{2}{|c|}{$1.87 \pm 0.92$} \\
\hline Sex of lived children & & \\
\hline -Males & 73 & 36.5 \\
\hline -Females & 59 & 29.5 \\
\hline - Males \& females & 68 & 34.0 \\
\hline
\end{tabular}

Table (3): Distribution of the studied women according to their history of last pregnancy $(n=200)$

\begin{tabular}{|l|c|c|}
\hline \multicolumn{1}{|c|}{ History of last pregnancy } & No. & \% \\
\hline No. of follow-up visits & & 0.5 \\
\hline- None & 1 & 34.5 \\
\hline$-\quad 4$ visits & 69 & 65.0 \\
\hline$-\geq 4$ visits & 130 & \\
\hline Presence of complications during pregnancy & 141 & 70.5 \\
\hline- Yes & 59 & 29.5 \\
\hline- No & & \\
\hline Type of complications: & 2 & 1.4 \\
\hline- Vaginal bleeding & 47 & 33.3 \\
\hline- Anemia & 53 & 37.6 \\
\hline- Preeclampsia & 30 & 21.3 \\
\hline- Hyperemesis graviderum & 9 & 6.4 \\
\hline- Gestational Diabetes & 0 & 0.0 \\
\hline- Other & & \\
\hline Received information about dangerous signs of pregnancy? & 177 & 88.5 \\
\hline- Yes & 23 & 11.5 \\
\hline- No & & \\
\hline Received information about the signs of approaching labor? & 121 & 60.5 \\
\hline$-\quad$ Yes & 79 & 39.5 \\
\hline- No & & \\
\hline Received information about the delivery place? & 94 & 47.0 \\
\hline- Yes & 106 & 53.0 \\
\hline- No & & \\
\hline
\end{tabular}




\begin{tabular}{|l|c|c|}
\hline History of last pregnancy & No. & \% \\
\hline Received information about preparation for childbirth? & & \\
\hline$-\quad$ Yes & 135 & 67.5 \\
\hline$-\quad$ No & 65 & 32.5 \\
\hline Source of information? & & \\
\hline- Obstetrician & 91 & 45.5 \\
\hline- Nurse/midwife & 59 & 29.5 \\
\hline- Daya & 2 & 1.0 \\
\hline- Parents and relatives & 30 & 15.0 \\
\hline- Friends and neighbors & 11 & 5.5 \\
\hline- Mass media & 7 & 3.5 \\
\hline- Other & 0 & 0.0 \\
\hline
\end{tabular}

Table (4): Distribution of the studied women according to their history of last delivery $(n=200)$

\begin{tabular}{|c|c|c|}
\hline History of last delivery & No. & $\%$ \\
\hline \multicolumn{3}{|l|}{ Place of delivery } \\
\hline- Home & 5 & 2.5 \\
\hline- Hospital & 150 & 75.0 \\
\hline - health center & 45 & 22.5 \\
\hline \multicolumn{3}{|l|}{ Attendant person } \\
\hline - Obstetrician & 104 & 52.0 \\
\hline$-\quad$ Nurse/midwife & 91 & 45.5 \\
\hline - Daya & 4 & 2.0 \\
\hline- Other & 1 & 0.5 \\
\hline \multicolumn{3}{|l|}{ Reasons for choosing this place in previous deliveries } \\
\hline- Availability of trained health care providers & 66 & 33.0 \\
\hline - Proximity & 18 & 9.0 \\
\hline - Economic & 34 & 17.0 \\
\hline - Security & 36 & 18.0 \\
\hline- Availability of facilities & 46 & 23.0 \\
\hline \multicolumn{3}{|l|}{ Presence of complications during childbirth? } \\
\hline- Yes & 79 & 39.5 \\
\hline$-\mathrm{No}$ & 121 & 60.5 \\
\hline \multicolumn{3}{|l|}{ Type of complications: } \\
\hline - Vaginal bleeding & 8 & 10.1 \\
\hline - Perineal lacerations & 61 & 77.2 \\
\hline - Premature rupture of membrane & 6 & 7.6 \\
\hline - Obstructed labor & 4 & 5.1 \\
\hline - Other & 0 & 0.0 \\
\hline \multicolumn{3}{|l|}{ Presence of complication during postpartum: } \\
\hline- Yes & 60 & 30.0 \\
\hline$-\mathrm{No}$ & 140 & 70.0 \\
\hline \multicolumn{3}{|l|}{ Type of complications } \\
\hline$-\mathrm{PPH}$ & 12 & 20.0 \\
\hline- Wound infection & 0 & 0.0 \\
\hline- DVT & 19 & 31.7 \\
\hline - Puerperal sepsis & 24 & 40.0 \\
\hline- Other & 5 & 8.3 \\
\hline
\end{tabular}


Table (5): Distribution of the studied women according to their total knowledge score $(\mathbf{n}=200)$ :

\begin{tabular}{|l|c|c|}
\hline \multicolumn{1}{|c|}{ Knowledge } & No. & $\%$ \\
\hline Poor $(0->14)$ & 84 & 42.0 \\
\hline Fair $(14->28)$ & 116 & 58.0 \\
\hline Good $(28-42)$ & 0 & 0.0 \\
\hline Total score & \multicolumn{2}{|c|}{$3.0-21.0$} \\
\hline Min. - Max. & \multicolumn{2}{|c|}{$14.06 \pm 3.51$} \\
\hline Mean \pm SD. & \multicolumn{2}{|c|}{$7.14-50.0$} \\
\hline Percent score & $33.46 \pm 8.37$ \\
\hline Min. - Max. & \multicolumn{2}{|c|}{} \\
\hline Mean \pm SD. & \multicolumn{2}{|c|}{3.0} \\
\hline
\end{tabular}

Table (6): Distribution of the studied women according to Preferences of future delivery place $(\mathbf{n}=200)$

\begin{tabular}{|l|c|c|}
\hline \multicolumn{1}{|c|}{ Preferences of future delivery place } & No. & $\%$ \\
\hline Preferred place for future delivery & & \\
\hline Home & 9 & 4.5 \\
\hline Governmental hospital & 48 & 24.0 \\
\hline Private hospital & 68 & 34.0 \\
\hline Family health center & 21 & 10.5 \\
\hline Private clinic & 54 & 27.0 \\
\hline Reasons & & \\
\hline Proximity & 12 & 6.0 \\
\hline Security & 48 & 24.0 \\
\hline The availability of enough supplies and facilities & 37 & 18.5 \\
\hline Availability of trained health care providers & 59 & 29.5 \\
\hline Economics & 24 & 12.0 \\
\hline Good attitude and way of communication & 20 & 10.0 \\
\hline
\end{tabular}

Table (7): Relation between woman's overall knowledge about delivery places and different parameters $(n=200)$

\begin{tabular}{|c|c|c|c|c|c|c|}
\hline \multirow{3}{*}{ Socio-demographic data } & \multicolumn{4}{|c|}{ Knowledge level } & \multirow{3}{*}{ Test of Sig. } & \multirow{3}{*}{$\mathbf{P}$} \\
\hline & \multicolumn{2}{|c|}{$\begin{array}{c}\text { Poor }(0->14) \\
(n=84)\end{array}$} & \multicolumn{2}{|c|}{$\begin{array}{c}\text { Fair }(14->28) \\
(n=116)\end{array}$} & & \\
\hline & No. & $\%$ & No. & $\%$ & & \\
\hline \multicolumn{7}{|l|}{ Age } \\
\hline$-<25$ & 32 & 38.1 & 16 & 13.8 & \multirow{3}{*}{$\begin{array}{c}\chi^{2}= \\
16.729\end{array}$} & \multirow{3}{*}{$<0.001^{*}$} \\
\hline$-25-<35$ & 39 & 46.4 & 82 & 70.7 & & \\
\hline$-\geq 35$ & 13 & 15.5 & 18 & 15.5 & & \\
\hline \multicolumn{7}{|l|}{\begin{tabular}{|l|} 
Educational level \\
\end{tabular}} \\
\hline - Illiterate / read and write & 2 & 2.4 & 11 & 9.5 & \multirow{5}{*}{$\begin{array}{c}\chi^{2}= \\
41.161^{*}\end{array}$} & \multirow{5}{*}{$<0.001^{*}$} \\
\hline - primary / preparatory & 20 & 23.8 & 6 & 5.2 & & \\
\hline - Secondary or equivalent & 47 & 56.0 & 36 & 31.0 & & \\
\hline - University education & 15 & 17.9 & 60 & 51.7 & & \\
\hline - Postgraduate studies & 0 & 0.0 & 3 & 2.6 & & \\
\hline \multicolumn{7}{|l|}{ Current residence } \\
\hline - Rural & 61 & 72.6 & 36 & 31.0 & \multirow{2}{*}{$\begin{array}{c}\chi^{2}= \\
33.730^{*}\end{array}$} & \multirow{2}{*}{$<0.001^{*}$} \\
\hline - Urban & 23 & 27.4 & 80 & 69.0 & & \\
\hline \multicolumn{7}{|l|}{ Place of delivery } \\
\hline - Home & 2 & 2.4 & 3 & 2.6 & \multirow{3}{*}{$\begin{array}{c}\chi^{2}= \\
0.631\end{array}$} & \multirow{3}{*}{$\begin{array}{l}{ }_{\mathrm{MC}}^{\mathrm{MC}}= \\
0.823\end{array}$} \\
\hline - Hospital & 61 & 72.6 & 89 & 76.7 & & \\
\hline - Health center & 21 & 25.0 & 24 & 20.7 & & \\
\hline
\end{tabular}




\begin{tabular}{|c|c|c|c|c|c|c|}
\hline \multirow{3}{*}{ Socio-demographic data } & \multicolumn{4}{|c|}{ Knowledge level } & \multirow{3}{*}{ Test of Sig. } & \multirow{3}{*}{$\mathbf{P}$} \\
\hline & \multicolumn{2}{|c|}{$\begin{array}{l}\text { Poor }(0->14) \\
\quad(n=84)\end{array}$} & \multicolumn{2}{|c|}{$\begin{array}{l}\text { Fair }(14->28) \\
\quad(n=116)\end{array}$} & & \\
\hline & No. & $\%$ & No. & $\%$ & & \\
\hline \multicolumn{7}{|l|}{ Preferred place for future delivery } \\
\hline - Home & 8 & 9.5 & 1 & .9 & \multirow{5}{*}{$\begin{array}{c}\chi^{2}= \\
11.646^{*}\end{array}$} & \multirow{5}{*}{$0.020^{\circ}$} \\
\hline -Governmental hospital & 17 & 20.2 & 31 & 26.7 & & \\
\hline - Private hospital & 27 & 32.1 & 41 & 35.3 & & \\
\hline -Family health center & 12 & 14.3 & 9 & 7.8 & & \\
\hline - Private clinic & 20 & 23.8 & 34 & 29.3 & & \\
\hline \multicolumn{7}{|l|}{ Reasons for choice } \\
\hline - Proximity & 4 & 4.8 & 8 & 6.9 & \multirow{6}{*}{$\begin{array}{c}\chi^{2}= \\
14.508^{*}\end{array}$} & \multirow{6}{*}{$0.013^{*}$} \\
\hline - Security & 25 & 29.8 & 23 & 19.8 & & \\
\hline $\begin{array}{l}\text { The availability of enough supplies } \\
\text { and facilities }\end{array}$ & 21 & 25.0 & 16 & 13.8 & & \\
\hline $\begin{array}{l}\text { - The availability of trained health care } \\
\text { providers }\end{array}$ & 23 & 27.4 & 36 & 31.0 & & \\
\hline - Economic & 9 & 10.7 & 15 & 12.9 & & \\
\hline $\begin{array}{l}\text { Good attitude and way of } \\
\text { communication }\end{array}$ & 2 & 2.4 & 18 & 15.5 & & \\
\hline
\end{tabular}

$\chi^{2}:$ Chi square test MC: Monte Carlo FE: Fisher Exact $t$ : Student t-test $*$ : Statistically significant at $p \leq 0.05$

Table (1): Shows that About two-thirds of the subjects $(60.5 \%)$ aged from 25 to 35 years. In relation to their level of education, $41.5 \%$ had a secondary or equivalent, while only $6.5 \%$ of them were illiterate. About one-half of them $(53.5 \%)$ were housewives. In addition, the current residence was in rural areas among $48.5 \%$ of them. Furthermore, the type of family indicates that more than one - half $52 \%$ of them had nuclear family. Considering the family income/month, it had been elucidated that $49.5 \%$ of the studied group had just enough income, compared to $22.5 \%$ of them had not enough income.

Table (2): Illustrates that about $50.5 \%$ of the studied group had 3 and more pregnancy time, and $36 \%$ of them had 3 and more labor time. However, the mean of abortion of the studied sample was $0.58 \pm 0.66$. In addition, the mean of lived birth was $1.87 \pm 0.92$ and about $36.5 \%$ of them were male.

Table (3): Indicated the distribution of the studied women according to the history of last pregnancy. Concerning the number of follow-up visits, it was observed that about $65 \%$ of the studied subjects had four times or more follow-up visits. Regarding the complications that had occurred during pregnancy, about three-quarters of them $(70.5 \%)$ had complications. The $(37.6 \%, 33.3 \%$, and $21.3 \%)$ respectively. Regarding receiving information about danger signs of pregnancy, about $88.5 \%$ had information about it. Moreover, it was noticed that $60.5 \%$ had information about the signs of imminent labor. In relation to the place of birth, it was observed that $53 \%$ had no information about the place of birth.
Also, $67.5 \%$ of them had information about the preparation for childbirth. It was observed that the source of this information comes from doctors; nurses; parents and relatives $(45.5 \%, 29.5 \%, 15 \%)$ respectively.

Table (4): Illustrates the distribution of the studied women according to the history of the last delivery. About $75 \%$ of the studied group had delivered in hospitals. In addition, $52 \%$ of them delivered by a doctor and $45.5 \%$ by a nurse/midwife. The reasons for choosing this place for delivery were the availability of well-trained health care providers, availability of facilities and security $(33 \%, 23 \%, 18$ $\%)$ respectively. Concerning the complications that had occurred during childbirth, slightly less than twofifths $(39.5 \%)$ had complications. The majority of them $(77.2 \%)$ had lacerations and only $10 \%$ of them had vaginal bleeding. Regarding postpartum complications, $40 \%$ of them had puerperal sepsis. About one-third (31.7\%) had DVT and only $20 \%$ of them had post-partum hemorrhage.

Table (5): Explicates the percent distribution of women according to their total score of knowledge about delivery place. Fair knowledge was found among $58 \%$ of the studied subjects compared to $42 \%$ who had poor knowledge. However, none $(0 \%)$ of the studied subjects had good knowledge about delivery places.

Table (6): Shows the distribution of studied women according to preferences of future delivery places. The highest percentage of them (34\%) preferred to have their future delivery at private hospitals 
followed by $27 \%$ of them who preferred private clinics. It was surprising that only $4.5 \%$ preferred to have their future delivery at home. The most common reasons for choosing the future delivery places are the availability of trained health care providers $(29.5 \%)$; security (24\%), availability enough supplies and facilities $(18.5 \%)$.

Table (7): Shows that there is a statistically significant correlation between the women's overall knowledge level and different parameters like age, level of education, current residence, preferred setting for future delivery as well as the reasons for choice these places

\section{Discussion}

The delivery of a baby is a crucial stage in a woman life and her family. The health and well-being of the mother and child at birth control the future health and well-being of the entire family. However, the outcome of childbirth is not the only factor of significance in a mother's well-being. Some studies suggests that the way a woman experiences pregnancy and birth is also critical for a mother's relationship with her child and her future birth experiences (Cook \& Loomis, 2012). Women's choice of birthplace may be related to several factors that can have effects on the birthplace available to women and the corresponding choices they make. A comprehensive understanding of these factors is important to certify women's access to the most proper birth environment to accomplish the best maternal and fetal health outcomes. Hence, this study was carried out to explore the factors determining choice of delivery place among women of child bearing age (Regan et al., 2013).

On estimating the total score of knowledge about delivery places, the results of the present study revealed that slightly less than three - fifths of the study participants had a fair knowledge level regarding the delivery places (table 5). This implies that awareness of the existence and/or practices of delivery place stand not as an ultimate factor but is related to other factors determining the choice of delivery places among participants.

The current finding is consistent with the findings of many researchers, first is the study of Mukhtar et al. (2018) who had conducted a study titled " Factors influencing the choice of place of delivery among recently delivered women in tribal areas of district Srinagar: A cross sectional study". They had found that knowledge or awareness about the existence of the delivery place influenced the choice of delivery places. Therefore, the respondents select delivery places that they have appropriate knowledge about it. Secondly, the study was conducted by Egharevba et al. (2017). They had conducted a study titled "Factors influencing the choice of child delivery location among women attending antenatal care services and immunization clinic in southeastern Nigeria". Their findings revealed that knowledge of the health care providers about delivery places significantly influences the choice of the place of delivery. Moreover, the survey of Ravi et al. (2014) had conducted a study entitled "Does socio-demographic factors influence women's choice of delivery in rural areas of Tamilnadu State in India" emphasized that knowledge about maternal health services is important to identify the factors which lead to the choice of delivery places.

Regarding the preference of the birth setting, the minority of the study subjects had chosen the home as a place of birth. These results may be attributed to the fact that the majority of the study subjects were lived in urban areas, also their income is enough, so they preferred the private hospital than the home delivery. This result is consistent with the findings of Gebregziabher et al. (2019) they had investigated the factors determining the choice of place of delivery in Akordet town, Eritrea. Their results revealed that a minority of the study subject had chosen the home as a place of birth.

The result of the current study is not consistent with the findings of Kifle et al. (2018), they had conducted a study titled "Health facility or home delivery? Factors influencing the choice of delivery place among mothers living in rural communities of Eritrea". Their results revealed that the majority of the study subjects had chosen the home as a place of delivery. They had attributed their results to the socio-cultural context in which women live and how these factors affect their preferences in access to and use of health services.

The relationship between delivery places and sociodemographic characteristics:

Concerning age, the results of the current study showed that there was a statistically significant relation between age and the knowledge level regarding the delivery places. In which about twothirds of women who had fair knowledge level were aged from $20-<35$ years. This may be probably because older women felt that they have gathered some experience and they are fully aware of the advantages and disadvantages regarding the different delivery places. The current finding relatively coincides with the study of Envuladu et al. (2013) who conducted a study titled "Place of delivery among pregnant women in Russia village of Jos North, Nigeria: achieving the MDGs 4 and 5", where they found that age is one of the factors significantly associated with the higher knowledge level regarding the different delivery places. 
In contrast, the result of the present study is not consistent with the findings of Scott (2018) who had conducted a study titled" Factors affecting home delivery among women living in remote areas of rural Zambia: a cross-sectional, mixed-methods analysis". The result reported that no statistically significant relation was observed between the age and the knowledge level regarding the chosen delivery places. Generally speaking, level of education is considered one of the most significant social variables that closely linked to one's feedback to life events such as childbirth, both physically and psychologically. However, having high educational background seems to have an association with the participants' choice of delivery places in the present study, where university-educated women had a fair knowledge level regarding the chosen delivery places.

This result may be attributed to many reasons maternal education is the most important determinants for health services use, as better educated women could have better access to information through reading and following media about maternal health care and they could have better knowledge about the advantages of maternal health care and pregnancy-related complications. Therefore, educated women are more aware of health problems, more knowledgeable about the availability of health care services, and more effectively maintain or achieve good health status.

This study result is almost congruent with the findings of Ali \& Chauhan (2020), they had conducted a study titled "Inequalities in the utilization of maternal health Care in Rural India: Evidences from National Family Health Survey III \& IV". They had reported that most of women who had high knowledge regarding the delivery place were highly educated.

As regarding women's occupation, the present study revealed that working women with fair knowledge levels were more than housewives. Furthermore, most of the women who had poor knowledge levels were housewives with no statistically significant relationship. The result of the current study is congruent with the finding of Ravi et al. (2014) they had conducted a study titled "Does sociodemographic factors influence women's choice of delivery in rural areas of Tamilnadu State in India". They had reported that there was no statistically significant relationship between the occupation and the knowledge level regarding the different delivery places. On the contrary, a previously mentioned study done by Samson (2012) who had revealed that there was no statistically significant relationship between the occupation and the knowledge level regarding the different delivery places.
On investigating the relationship between current residence and knowledge level regarding the delivery places, the results of the present study demonstrated a high statistically significant relation, where the urban women had a fair knowledge level than the rural women. This may be interpreted as the place of residence plays an important predictor to women's preference of place of delivery as living in urban areas increases the probability of pregnant women using of health facilities attended by trained professionals for delivery. The results of the current study are consistent with the finding of Bekuma (2020), they had investigated "Factors Affecting Choice of Childbirth Place among Childbearing Age Women in Western Ethiopia: A Community-Based Cross-Sectional Study". Their results showed that residence has a strong association with the choice of place of delivery, where urban residents' women had acceptable knowledge regarding the advantages and disadvantages of different delivery places.

\section{Conclusion:}

Based on the findings of the present study, it could be concluded that slightly less than three - fifths (58\%) of the studied subjects had fair knowledge level regarding the delivery places. Additionally, 58\% of them had chosen the hospitals whether private or governmental as a place for future delivery due to the availability of health care providers and good supplies and facilities. Moreover, they will choose the most affordable hospital available. A positive correlation was found between the knowledge about delivery places and age, education level and residence.

\section{Recommendations}

Based on the findings of the present study, the following recommendations are suggested:

- In- service training program should be carried out for nurses who are working in antenatal clinics to upgrade their knowledge to teach women about the knowledge of each delivery place and guide them for proper choice.

- Continuous monitoring of women's satisfaction with all aspects of care during delivery could aid in improvement of the quality of services and ultimately improve the women's attitude toward the different delivery places.

\section{References}

- Ali, B., \& Chauhan, S. (2020): Inequalities in the utilisation of maternal health Care in Rural India: Evidences from National Family Health Survey III \& IV. BMC public health, Vol. 20, No. (1), Pp. 369-369. 
- American Association of Birth Centers [AABC]. (2015):What is a birth center? . USA: AABC.

- Bekuma, T., Firrisa, B., \& Negero, M. (2020): Factors Affecting Choice of Childbirth Place among Childbearing Age Women in Western Ethiopia: A Community-Based Cross-Sectional Study. International Journal of Reproductive Medicine, Vol. 12, No. (4), Pp. 1-9.

- Campbell, O., Gipson, R., Issa, A., Matta, N., El Deeb, B., El Mohandes, A., \& Mansour, E. (2019): National maternal mortality ratio in Egypt halved between 1990 -2010. Bulletin of the World Health Organization, Vol. 83, No. (1), Pp. 462471.

- Cook, K., \& Loomis, C. (2012): The Impact of Choice and Control on Women's Childbirth Experiences. The Journal of perinatal education, Vol. 21, No. (3), Pp. 158-168.

- Coxon, K., Sandall, J., \& Fulop, N. J. (2015): How do pregnancy and birth experiences influence planned place of birth in future pregnancies? Findings from a longitudinal, narrative study. Birth, Vol. 42, No. (2), Pp. 141148.

- Dahlberg, U., \& Aune, I. (2013): The woman's birth experience---the effect of interpersonal relationships and continuity of care. Midwifery, Vol. 29, No. (4), Pp. 407-415.

- Egharevba, J., Pharr, J., van Wyk, B., \& Ezeanolue, E. (2017): Factors Influencing the Choice of Child Delivery Location among Women Attending Antenatal Care Services and Immunization Clinic in Southeastern Nigeria. International journal of $\mathrm{MCH}$ and AIDS, Vol. 6, No. (1), Pp. 82-92.

- Envuladu, E., Agbo, H. A., Lassa, S., Kigbu, J. H., \& Zoakah, A. (2013): Factors determining the choice of a place of delivery among pregnant women in Russia village of Jos North, Nigeria: Achieving the MDGs 4 and 5. International Journal of Medicine and Biomedical Research, Vol. 2, No., Pp. 23-27.

- Gebregziabher, N., Zeray, A., Abtew, Y., Kinfe, T., \& Abrha, D. (2019): Factors determining choice of place of delivery: analytical crosssectional study of mothers in Akordet town, Eritrea. BMC public health, Vol. 19, No. (1), Pp. 1-11.

- Kifle, M., Kesete, H., Gaim, H., Angosom, G., \& Araya, M. (2018): Health facility or home delivery? Factors influencing the choice of delivery place among mothers living in rural communities of Eritrea. Journal of Health, Population and Nutrition, Vol. 37, No. (1), Pp. 115.
- Larkin, P., Begley, C., \& Devane, D. (2017) : Women's preferences for childbirth experiences in the Republic of Ireland; a mixed methods study. BMC Pregnancy Childbirth, Vol. 17, No. (1), Pp. 19-19.

- Lowdermilk, D., Perry, S., \& Cashion, M. (2014) : Maternity Nursing (7th ed.). St. Louis: Elsevier Health Sciences.

- Olza, I., \& Leahy-Warren, P. (2018) :. Women's psychological experiences of physiological childbirth: a metasynthesis. BMJ, Vol. 8, No. (10), Pp. 1-11.

- Mukhtar, M., Nelofar, M., Quansar, R., Khan, S., \& Bashir, H. (2018) : Factors influencing the choice of place of delivery among recently delivered women in tribal areas of district Srinagar: A cross sectional study. Journal of Medical Science and Clinical Research, Vol. 6, No. (6), Pp. 356-361.

- Murray, S., \& McKinney, E. (2014) : Foundations of maternal-newborn and women's health nursing (6th ed ed.). Sunders: Elsevier Health Sciences.

- Pillitteri, A. (2010) : Maternal \& child health nursing: care of the childbearing \& childrearing family (6th ed.). New York: Lippincott Williams $\&$ Wilkins.

- Ravi, R., Kulasekaran, R., \& Ravi, R. (2014): Does socio-demographic factors influence women's choice of place of delivery in rural areas of Tamilnadu state in India. American Journal of Public Health Research, Vol. 2, No. (3), Pp. 7580.

- Regan, M., McElroy, K., \& Moore, K. (2013) : Choice? Factors That Influence Women's Decision Making for Childbirth. The Journal of perinatal education, Vol. 22, No. (3), Pp. 171-180.

- Scott, N., \& Henry., E. (2018) :Factors affecting home delivery among women living in remote areas of rural Zambia: a cross-sectional, mixedmethods analysis'. International Journal of Women's Health, Vol. 10, No. (7), Pp. 589-601.

- Steel, A., Sibbritt, D., Adams, J., Frawley, J., Broom, A., \& Gallois, C. (2014) : The association between women's choice of birth setting and their use of CAM during labor and birth. The Journal of Alternative and Complementary Medicine, Vol. 20, No. (5), Pp. A20-A25.

- World Health Organization [WHO]. (2015). Trends in maternal mortality: 1990-2015: estimates from WHO, UNICEF, UNFPA, World Bank Group and the United Nations Population Division: executive summary (No. WHO/RHR/15.23). Geneva: WHO. 
- Zielinski, R., Ackerson, K., \& Kane Low, L. (2015) : Planned home birth: benefits, risks, and opportunities. Int J Womens Health, Vol. 7, No., Pp. 361-377. 